\title{
Carcinoma de células escamosas en linfonódulo mandibular diagnosticado a la inspección en matadero como tuberculosis bovina ${ }^{\#}$
}

\author{
Squamous cell carcinoma in a mandibular lymph node diagnosed as bovine \\ tuberculosis during slaughterhouse inspection \\ C Lecocq ${ }^{a}$, P Zurita ${ }^{a}$, M Quezadab, D Muñoz ${ }^{\text {* }}$ \\ ${ }^{\mathrm{a} C}$ Complejo de Laboratorios y Estaciones Cuarentenarias Agrícola y Pecuaria, Servicio Agrícola y Ganadero, \\ Lo Aguirre, Santiago, Chile. \\ bFacultad de Ciencias Veterinarias, Departamento de Patología y Medicina Preventiva, Universidad de Concepción, \\ Chillán, Chile.
}

\section{SUMMARY}

The diagnosis of bovine tuberculosis (TBC) involves the combination of several techniques to obtain an accurate diagnosis. Among them, the inspection of the animal body at the slaughterhouse is, perhaps, one of the most important for the surveillance of bovine TBC. In Chile, the guidelines for this practice appear in the Official Inspection Manual of the Agricultural and Livestock Service (SAG). Nevertheless, there are wrong interpretations of findings at the slaughterhouse. This study describes a squamous cell carcinoma in the submandibular lymph node of a cow that was initially diagnosed as tuberculosis, based on the presence of caseous necrosis and mineralization detected during postmortem gross examination. Squamous cell carcinoma is a common tumor of white-faced cows such as Hereford, which tend to metastasize to regional lymph nodes like the mandibular lymph node.

Palabras clave: tuberculosis, seguridad alimentaria, inspección de matadero, diagnóstico.

Key words: tuberculosis, food safety, abbattoir inspection, diagnosis.

\section{INTRODUCCIÓN}

El agente etiológico de la tuberculosis bovina es Mycobacterium bovis, que a su vez puede afectar al ser humano (Lüchter 2004, Biet y col 2005). La enfermedad se caracteriza por un cuadro crónico con la formación de tubérculos conocidos como granulomas tuberculosos, los cuales se ubican principalmente en el pulmón y linfonódulos retrofaríngeos, bronquiales y mediastínicos (Casswell y Williams 2007). Sin embargo, en las infecciones digestivas estos granulomas pueden encontrarse en la mucosa digestiva, principalmente en yeyuno o íleon, y los consiguientes linfonódulos mesentéricos, desde aquí la enfermedad se puede generalizar al hígado, bazo y el mesenterio, no descartándose otros órganos (Neill y col 1994, Sierra y col 2004).

La identificación de animales con tuberculosis, principalmente vacunos, se realiza en el animal vivo por medio de la prueba de tuberculina, a través de la reacción de hipersensibilidad retardada (Lüchter 2004). La infección con frecuencia puede ser subclínica, no obstante, en animales

\footnotetext{
Aceptado: 07.12.2011.

\# Financiado por el Servicio Agrícola y Ganadero (SAG).

* dennis.munoz@sag.gob.cl
}

enfermos se puede observar debilidad, anorexia, emaciación, disnea, aumento de tamaño de los linfonódulos y tos, principalmente en aquellos animales con cuadros agudos. Así la erradicación de la tuberculosis bovina reside en la detección de animales positivos y el subsecuente envío a matadero para su eliminación (Aranaz y col 2006).

En Chile, durante el año 2008 se decidió implementar el proyecto nacional de control y erradicación de la tuberculosis bovina, el cual establece estrategias y objetivos definidos según lo señalado en esquemas internacionales (Paredes 2008). Dentro de los cuales, la inspección post mortem de las canales bovinas en matadero, amparada en la Ley $\mathrm{N}^{\circ} 18.755$ que faculta al Servicio Agrícola y Ganadero (SAG) para mantener sistemas de vigilancia, representa gran parte del decomiso de vísceras y canales al momento de encontrar cualquier tipo de lesión granulomatosa. Éstas, según el instructivo técnico de inspección del SAG (instructivo técnico TBC/T2 ${ }^{1}$ ), deben enfocarse en los linfonódulos del aparato respiratorio, los cuales deben presentar lesiones características como por ejemplo la presencia de tubérculos pequeños o grandes, solitarios o múltiples y que pueden involucrar un órgano, un sistema o con distribución multisistémica. Otra característica importante en el bovino es la presencia de un material

www.sag.cl 
caseoso amarillento, que a menudo está calcificado hasta cierto grado, y que al corte con un instrumento de diéresis se siente un caseum impregnado de sales de calcio (Sierra y col 2004).

Otro punto importante de análisis, en las lesiones macroscópicas ocasionadas por bacterias del género Mycobacterium, es la diferencia existente en la formación de granulomas ocasionados por otras especies como M. avium en donde la calcificación rara vez ocurre; por otro lado, al corte la lesión tiene aspecto neoplásico con escasos focos caseosos, y aunque existe una fibrosis difusa la formación de capsula es más bien rara (Primm y col 2004).

Por otra parte, especial interés tiene el carcinoma de células escamosas, en cuanto al diagnóstico diferencial frente a TBC bovina, por cuanto es el de mayor prevalencia en el ganado bovino (80\%), y donde en un 5\% de los casos realiza metástasis a los linfonódulos regionales parotidios y mandibulares (Aiello y col 2005).

Con los antecedentes anteriormente expuestos, se puede inferir que el diagnóstico erróneo de la enfermedad ocurre, aun cuando en la actualidad existen otros métodos de diagnóstico mucho más sensibles y específicos, que van desde el uso de la tuberculina, pasando por la histopatología y llegando en la actualidad a la técnica de reacción en cadena de la polimerasa (PCR) o el inmunoensayo de Interferón Gamma (Michel 2008, Michel y col 2010).

En este reporte de caso se presenta el hallazgo de una lesión en el linfonódulo mandibular izquierdo diagnosticada post mortem como tuberculosis bovina, la cual fue fijada para histopatología y congelada para la detección de M. bovis por PCR.

\section{MATERIAL Y MÉTODOS}

\section{ORIGEN DE LA MUESTRA}

La muestra fue obtenida de un bovino hembra, de raza y edad no indicadas (ID 1097), proveniente de la Región del Maule, al cual se le detectó, al momento del servicio, una lesión de tipo nodular e irregular, con múltiples zonas de color blanquecino en el linfonódulo mandibular izquierdo y que al corte se apreció calcificada.

\section{HISTOPATOLOGÍA}

La muestra fue remitida al Laboratorio de Patología Animal del Complejo de Laboratorios y Estaciones Cuarentenarias Agrícola y Pecuaria en Lo Aguirre, fijada en formol tamponado al 10\% (pH 7). Posteriormente fue deshidratada y embebida en parafina, seccionada a $4 \mu \mathrm{m}$ de espesor, teñida con hematoxilina-eosina según el protocolo de Luna (1968) y finalmente fue observada al microscopio óptico (AXIO. Imagen. A1. Zeiss ${ }^{\circledR}$ ).
REACCIÓN EN CADENA DE LA POLIMERASA (QPCR) CUANTITATIVA PARA LA IDENTIFICACIÓN DE $M$. BOVIS Y M. AVIUM

La muestra congelada ingresó al Laboratorio de Micobacterias del Complejo de Laboratorios y Estaciones Cuarentenarias Agrícola y Pecuaria en Lo Aguirre el 12 de noviembre del 2009. Posteriormente se realizó extracción de DNA a partir de la lesión nodular, la cual se efectuó mediante el kit High Pure PCR Template Preparation (Roche ${ }^{\circledR}$ ), el que fue modificado en la primera parte de su metodología, según se describe a continuación. En un microtubo de $2 \mathrm{ml}$ que contiene perlas de zirconia de diámetros 0,1 mm y $1 \mathrm{~mm}$ se depositan $250 \mathrm{mg}$ de lesión sospechosa más $400 \mu \mathrm{l}$ de buffer de lisis del kit.

Las muestras son sometidas a la acción de un disruptor celular (The Mini-BeadBeater-16, Biospec ${ }^{\circledR}$ ) (3450 oscilaciones/minuto) durante 3 min y luego se centrifugan durante $5 \mathrm{~min}$ a $10000 \mathrm{rpm} .200 \mu \mathrm{l}$ del sobrenadante son traspasados a un nuevo tubo. El proceso continúa según el manual de instrucciones del kit High Pure PCR Template Preparation $\left(\right.$ Roche $\left.^{\circledR}\right)$. Se utilizó el kit diagnóstico Boviman ${ }^{\circledR}$, Roche (equipo ABI 7500 Fast bajo patentación).

\section{RESULTADOS Y DISCUSIÓN}

\section{DESCRIPCIÓN DEL CASO}

Principales hallazgos macroscópicos. La muestra recepcionada correspondió a un linfonódulo seccionado con un tamaño de 5,0 x 3,0 x 3,0 centímetros. Al corte, el tejido presentó lesiones nodulares e irregulares múltiples de color blanquecino, no calcificadas, las cuales estaban diseminadas en todo el tejido (figura 1). Lo anterior puede ser indicativo de tuberculosis en bovino; sin embargo, según el instructivo técnico del Servicio Agrícola y Ganadero las lesiones son con más frecuencia encontradas en los pulmones y nódulos linfáticos del tracto respiratorio (SAG 2004). Por esto, cualquier lesión sospechosa de tuberculosis bovina hallada en algún linfonódulo periférico se deberá corroborar con la inspección de dichos nódulos linfáticos. Sin perjuicio de lo anterior, se han descrito casos de tuberculosis bovina digestiva en donde puede no estar afectado el sistema respiratorio del animal (Sierra y col 2004). Cabe destacar que no se encontraron otros linfonódulos afectados en este animal, por lo que un diagnóstico más asertivo fue complicado.

Posterior a la inspección exhaustiva del linfonódulo afectado, lo que incluye laminar el tejido en cortes de $2 \mathrm{~mm}$ de grosor, si aún existe la sospecha, la muestra deberá ser enviada al laboratorio para realizar pruebas complementarias (histopatología, aislamiento por cultivo y técnicas moleculares), que permitan dilucidar la presencia del agente causante de la tuberculosis bovina $\mathrm{u}$ otro miembro del género Mycobacterium, por cuanto existen 


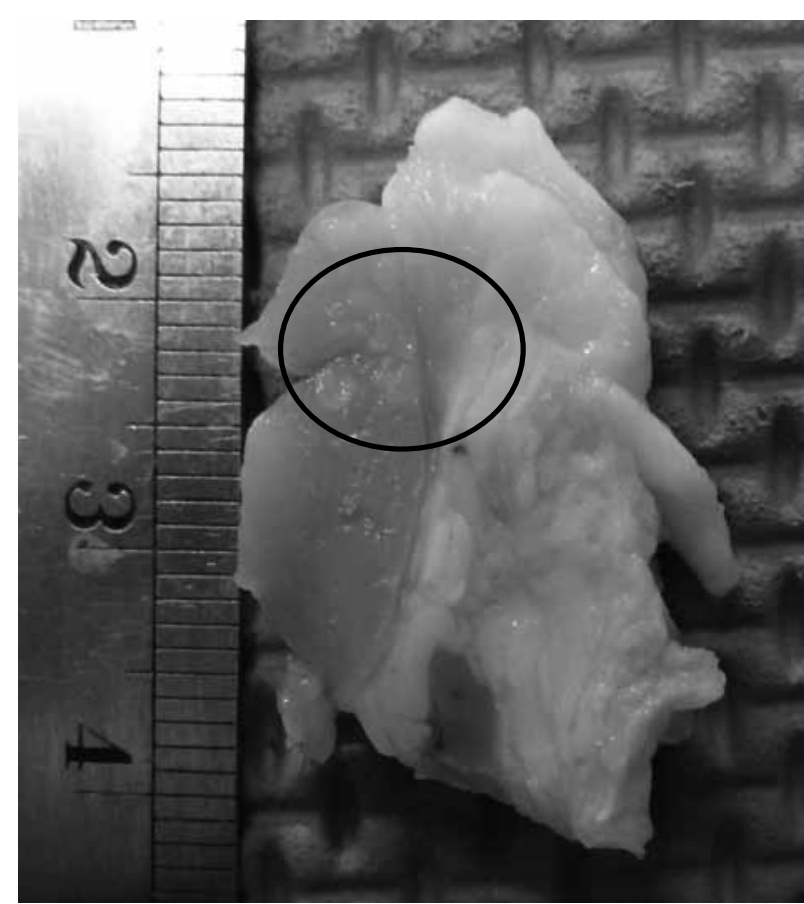

Figura 1. Linfonódulo mandibular decomisado por lesiones interpretadas como de tipo granulomatosas $(\mathrm{O})$.

Mandibular lymph node condemned due to lesions interpreted as granulomatosus $(\mathrm{O})$ diversos reportes de lesiones granulomatosas ocasionadas por micobacterias ambientales (Primm y col 2004).

Principales hallazgos microscópicos. El tejido conservaba pequeñas zonas de tejido linfoide constituidas por folículos con centros germinales dispersos y escasos, algunos de ellos activos. Sin embargo, la mayor parte del tejido estaba constituido por tejido heterotípico de aspecto neoplásico distribuido en los senos y espacios del tejido. Este tejido presentó características epiteliales con patrón de crecimiento papilar. Se observó gran cantidad de focos metastásicos compuestos por islas, cordones y trabéculas de células epiteliales invasivas, correspondientes principalmente a queratinocitos bien diferenciados, los cuales presentaban un núcleo y citoplasma prominentes, núcleos hipercromáticos con cromatina agrupada en la periferia de la carioteca y nucléolo de gran tamaño (figuras 2 y 3 ). El índice mitótico apreciado fue bajo (3 mitosis por campo a 200X). Algunos de los centros neoplásicos proliferativos presentaban gran cantidad de queratina suelta y prominentes perlas córneas, lo cual a la inspección macroscópica puede ser confundido con el caseum impregnado de calcio, característico de los granulomas de TBC, motivo por el cual al momento de la inspección el linfonódulo fue enviado al laboratorio central

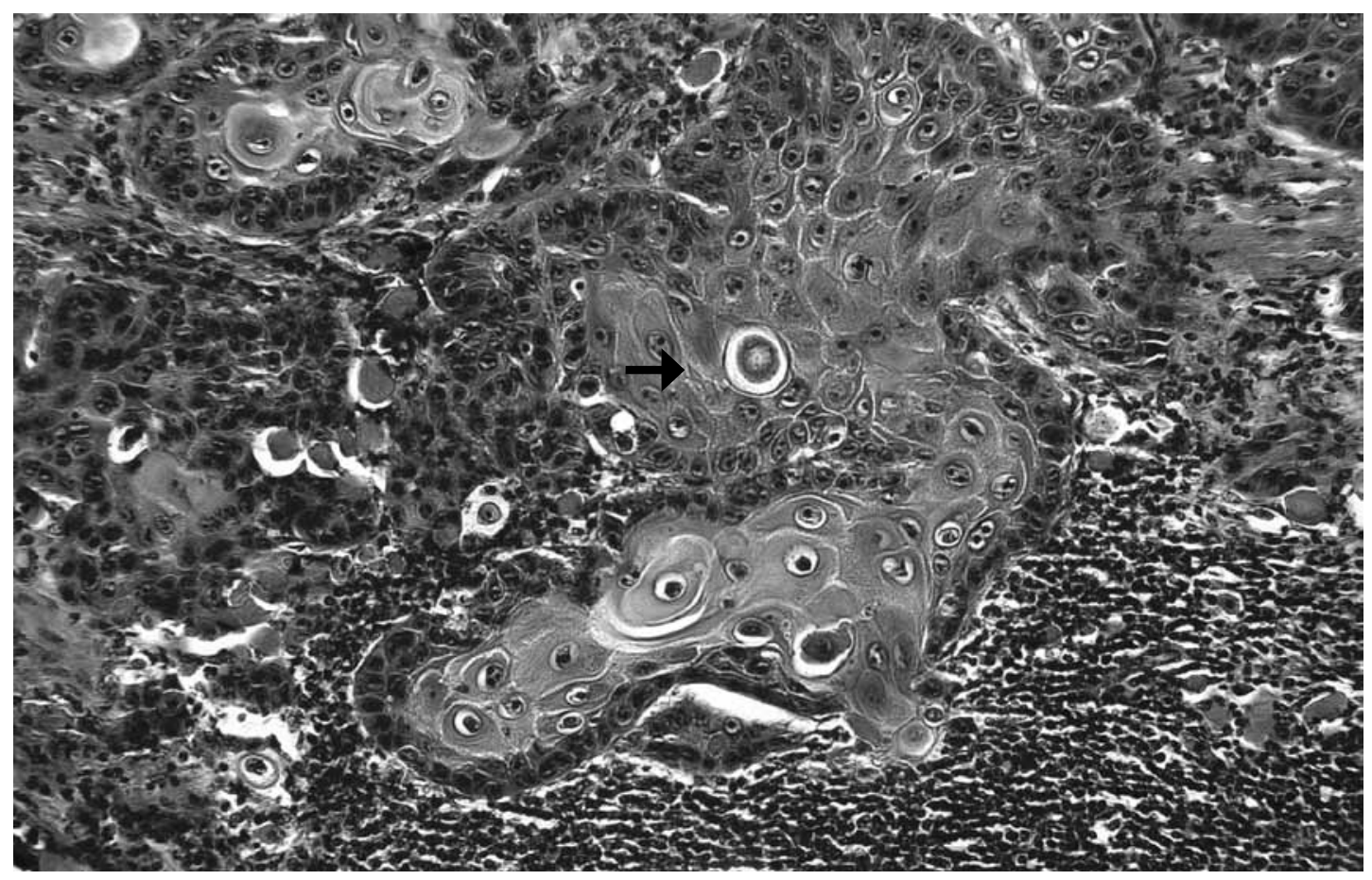

Figura 2. Metástasis en linfonódulo regional mandibular de un carcinoma de células escamosas. Se aprecian cordones de células epiteliales del estrato basal y espinocelular, con queratinización de células individuales (queratinocitos) $(\rightarrow)$. 100X.

Metastasis of squamous cell carcinoma in mandibular lymph node. Cords of epithelial basal and squamous layer cells, with keratinization of individual cells (keratinocyte) $(\longrightarrow$ ). 100X. 


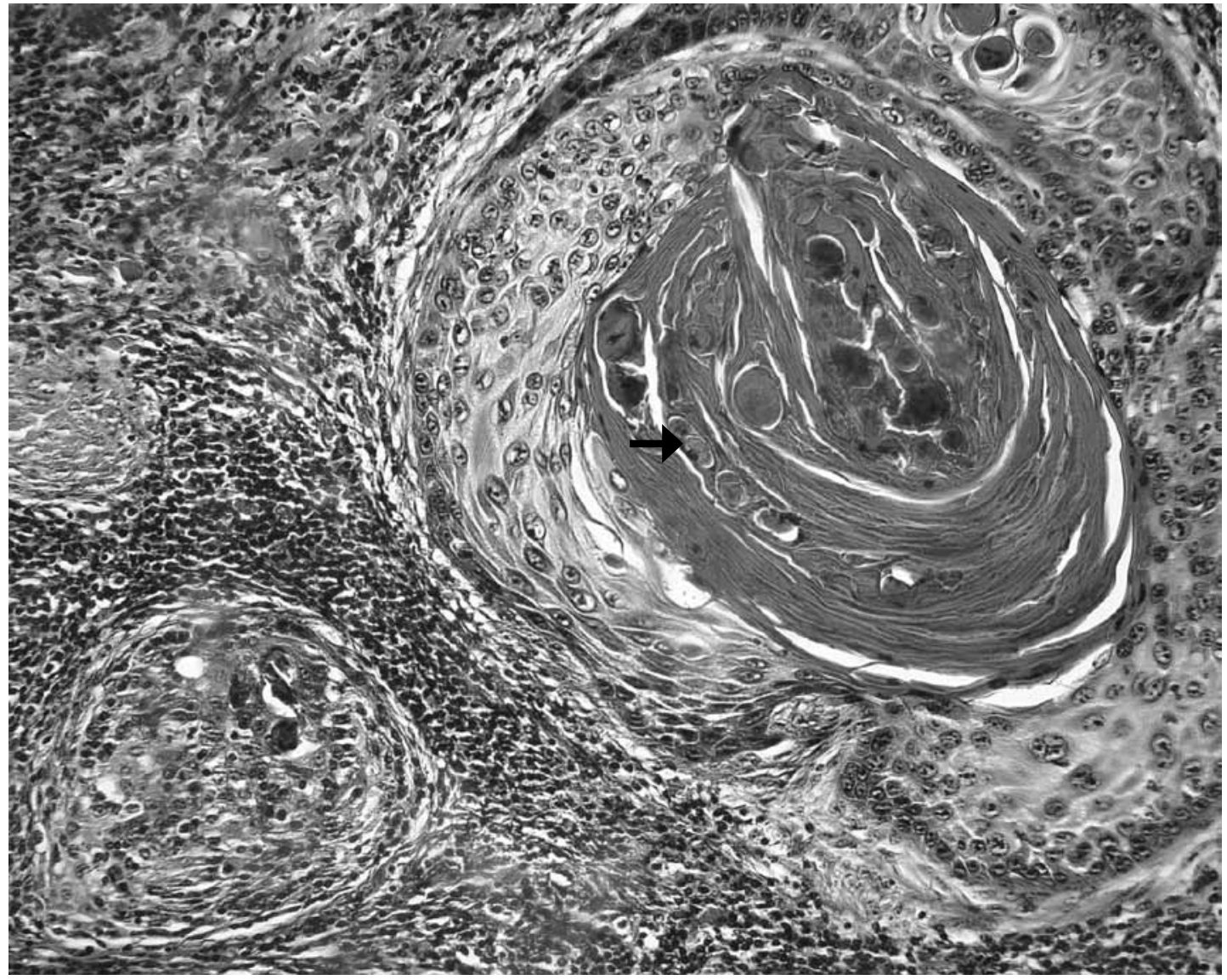

Figura 3. Formación de una gran perla córnea $(\rightarrow$ ) característica de un carcinoma de células escamosas, en medio del parénquima del linfonódulo mandibular. 400X.

Formation of a large squamous pearl $(\longrightarrow$ ), characteristic of a squamous cell carcinoma in the parenchyma of a mandibular lymph node. $400 \mathrm{X}$.

del SAG (Lo Aguirre) para realizar análisis complementarios, como lo indica el protocolo de toma y envío de muestras granulomatosas I-PP-VE-011 (Araya 2009)2.

$\mathrm{El}$ aspecto de las células tumorales, los patrones de crecimiento y la localización dentro del linfonódulo coinciden con la descripción de un carcinoma de células escamosas (Donald 2002).

Este tipo de tumor, en el ganado bovino, se caracteriza por presentarse en animales de una edad superior a los 7 años, en áreas sin pigmentación a nivel de la cara, y que por lo general hace metástasis a los nódulos linfáticos regionales como son el parotídeo y el mandibular (Aiello y col 2005).

Reacción en cadena de la polimerasa ( $q P C R)$ cuantitativa. El presente caso resultó negativo para las especies

\footnotetext{
http://www.sag.gob.cl/common/asp/pagAtachadorVisualizador.as p?argCryptedData $=$ GP1TkTXdhRJAS2Wp3v88hPya3Gv9bId9q8 $9 \mathrm{cmzNMQGw} \% 3 \mathrm{D} \& \operatorname{argModo}=\& \arg O r i g e n=B D \& \operatorname{argFlag}$ YaGra bados=\&argArchivoId=17960 Fecha de consultado 22 septiembre 2011
}

M. bovis y M. avium. Además de la alta sensibilidad y especificidad de esta técnica (Grant y col 2000), ésta presenta la ventaja de entregar un resultado mucho más rápido que el cultivo convencional. Por tal motivo, Liébana y col (1995) lo recomiendan como técnica de diagnóstico de tamizaje o screening.

La razón de la inexistencia de cultivo en este reporte de caso se debe primero al resultado negativo de la prueba molecular, y segundo, a los hallazgos histopatológicos, que no concordaron con una lesión granulomatosa típica de tuberculosis. Lo anterior deja en evidencia que el diagnóstico diferencial de tuberculosis bovina versus otras patologías, incluyendo el diagnóstico diferencial con otros miembros el género Mycobacterium, son de capital relevancia al momento de la inspección en matadero (Michel 2008). Por tal motivo, es importante a futuro esclarecer el diagnóstico fidedigno y certero de los principales hallazgos mal diagnosticados como lesiones tuberculosas en matadero, por cuanto se genera un conocimiento valioso en cuanto a la estadística relacionada a las principales patologías que se confunden con lesiones tuberculosas, así como también para aquellos que realizan inspección en matadero. 


\section{RESUMEN}

El presente trabajo establece que el diagnóstico de tuberculosis (TBC) bovina comprende múltiples técnicas que en conjunto llegan a un diagnóstico certero, no obstante, la inspección en matadero es quizás una de las más relevantes en la vigilancia de la TBC bovina, por cuanto ésta debe abocarse a lo que indica el manual de inspección del Servicio Agrícola y Ganadero (SAG). Aún así, es posible encontrar interpretaciones erróneas de los hallazgos en matadero, que confunden al inspector y que instan a aumentar la rigurosidad de la inspección.

\section{AGRADECIMIENTOS}

Los autores desean agradecer al Departamento de Laboratorios y Estaciones Cuarentenarias Agrícola y Pecuaria, Lo Aguirre.

\section{REFERENCIAS}

Aiello S. 2005. The Merck Veterinary Manual. In: Dinsmore (ed). Bovine Eye Diseases: Cancer Eye. $8^{\text {th }}$ ed. DVM, ILM-CSU, Colorado State University, Colorado, USA, Pp 366-367.

Aranaz A, L De Juan, J Bezos, J Alvarez, B Romero, F Lozano, J Paramio, J López, A Mateos, L Domínguez. 2006. Assessment of diagnostic tools for eradication of bovine tuberculosis in cattle co-infected with Mycobacterium bovis and M. avium subsp. paratuberculosis. Vet Res 37, 593-606.

Araya C. 2009. Instructivo: Toma y envío de muestras para diagnóstico de tuberculosis bovina. I-PP-VE-011. Servicio Agrícola y Ganadero, Santiago, Chile, Pp 1-14.

Biet F, M Boschiroli, M Thorel, L Guilloteau. 2005. Zoonotic aspects of Mycobacterium bovis and Mycobacterium avium-intracellulare complex (MAC). Vet Res 36, 411-436.

Casswell JL, KJ Williams. 2007. Respiratory system. In: Grant Maxie M (ed). Jubb, Kennedy, and Palmer's, Pathology of domestic animals. $5^{\text {th }}$ ed. Elsevier Limited, Philadelphia, USA, Pp 523-653.
Donald J. 2002. Tumors of the skin and soft tissue. In: Meuten DJ (ed). Tumors of the domestic animals. $4^{\text {th }}$ ed. Iowa State Press, Ames, USA, Pp 46-54.

Grant I, M Yates. 2000. Improved detection of Mycobacterium avium subsp. paratuberculosis in milk by immunomagnetic PCR. Vet Microbiol 77, 369-378.

Liébana E, A Aranaz, A Mateos, M Vilafranca, E Gómez-Mampaso, J Tercero, J Alemany, G Suárez, M Domingo, L Domínguez. 1995. Simple and rapid detection of Mycobacterium tuberculosis complex organisms in bovine tissue samples by PCR. J Clin Microbiol 33, 33-36.

Lüchter F. 2004. Introducción al estudio de las enfermedades infecciosas. En: Enfermedades infecciosas de los rumiantes. Editorial Universitaria de la Patagonia, Buenos Aires, Argentina, Pp 123-131.

Luna L. 1968. Manual of histologic staining methods of the armed forces institute of pathology. $3^{\text {rd }}$ ed. McGraw-Hill Book Co., New York, USA, Pp 200.

Michel A. 2008. Mycobacterium fortuitum infection interference with Mycobacterium bovis diagnostics: natural infection cases and a pilot experimental infection. J Vet Diagn Invest 20, 501-503.

Michel AL, B Müller, PD Van Helden. 2010. Mycobacterium bovis at the animal-human interface: A problem, or not? Vet Microbiol 140, 371-381.

Neill S, J Pollok, D Bryson, J Hanna. 1994. Pathogenesis of Mycobacterium bovis infection in cattle. Vet Microbiol 40, 41-52.

Paredes L. 2008. Proyecto nacional de control y erradicación de tuberculosis bovina. Servicio Agrícola y Ganadero, Santiago, Chile, Pp 3-114.

Primm T, C Lucero, J Falkinham. 2004. Health impacts of environmental mycobacteria. Clin Microbiol Rev 17, 98-106.

SAG, Servicio Agrícola y Ganadero. 2010. Programa oficial de diagnóstico y saneamiento de tuberculosis bovina en predios proveedores de plantas lecheras de las regiones VIII, IX y X. TBC/T2. Departamento de Protección Pecuaria, Subdepartamento de Vigilancia Epidemiológica, Santiago, Chile.

Sierra M, L Ibarra, A Ruiz, A Lobos, M Quezada. 2004. Bases para la inspección de la tuberculosis bovina en matadero. Trama Impresores S. A., Talcahuano, Chile. 